\title{
Voltammetry as Analytical Technique in the Study and Quantitation of Several Food and Beverage Components: An Editorial
}

Aurelia Magdalena Pisoschi

University of Agronomic Sciences and Veterinary Medicine of Bucharest, Bucharest, Romania

*Corresponding author: Pisoschi AM, University of Agronomic Sciences and Veterinary Medicine of Bucharest, Faculty of Veterinary Medicine, Bucharest, Romania, Email: aureliamagdalenapisoschi@yahoo.ro

Rec date: Apr 29, 2015; Acc date: Apr 30, 2015; Pub date: May 04, 2015

Copyright: (C) 2015 Pisoschi AM. This is an open-access article distributed under the terms of the Creative Commons Attribution License, which permits unrestricted use, distribution, and reproduction in any medium, provided the original author and source are credited.

\section{Editorial}

Voltammetric measurements rely on applying a controlled potential variation, and consequently recording the intensity versus potential dependence (voltammogram).

There are various ways to impose a potential variation in time, and subsequently a series of voltammetric methods. Cyclic voltammetry relies on linearly scanning the potential in time, observing a triangular waveform variation [1-3]. Differential pulse voltammetry is based on two samplings of the current intensity for each potential pulse: one measurement before applying the pulse, and the second towards the end of the pulse period. In square-wave voltammetry, a square-wave is superimposed on the potential staircase sweep, the current intensity being recorded at the end of each potential change. This potential step technique allows minimizing charging current and provides improved sensitivity, as also happens in differential pulse voltammetry [3].

These electrochemical techniques are characterized by fastness, simplicity of both the instrumentation and the applied procedure, minumum sample pre-treatment and do not involve toxic wastes. They allow the determination of a series of food and beverage components, relying on their electroactivity $[4,5]$.

Ascorbic acid voltammetric determination is possible due to its facile oxidation to dehydroascorbic acid, involving the transfer of two protons and two electrons. Figure 1 illustrates a differential pulse voltammogram, with the obtained ascorbic acid peak.

A cyclic voltammetric method for ascorbic acid determination used single-walled carbon nanotube/ $\mathrm{ZnO}$ modified glassy carbon electrode. The developed modified electrode exhibited better electroactivity, as well as better sensitivity and selectivity when compared to the $\mathrm{ZnO}$ modified electrode or to the bare glassy carbon electrode. The reported detection limit for the modified electrode was $85 \mu \mathrm{M}$. The observed good linear dependence between the intensity of the anodic peak and the square root of the potential scan rate indicates that the analyte's electro-oxidation is a diffusion controlled process. The linear range of analytical response corresponded to $0.2-10 \mathrm{mM}$. Experiments performed with the single-walled carbon nanotube/ZnO modified glassy carbon electrode in $0.1 \mathrm{M}$ potassium dihydrogen phosphate solution, showed that increasing the temperature within the range $20^{\circ} \mathrm{C}-85^{\circ} \mathrm{C}$, resulted in an increase of the peak current [6].

A differential pulse polarographic method based on the carminic acid reduction at dropping mercury electrode was studied. Measurements were carried out in Britton-Robinson buffer solution $\mathrm{pH}=2.0$. A linear dependence between the peak current intensity (obtained at $-489 \mathrm{mV}$ potential value) and the analyte concentration was observed in the range 1-90 $\mu \mathrm{M}$, and the detection limit was 0.16 $\mu \mathrm{M}$. The quantitation of carmine in spiked commercially available strawberry flavored milk was performed [7].

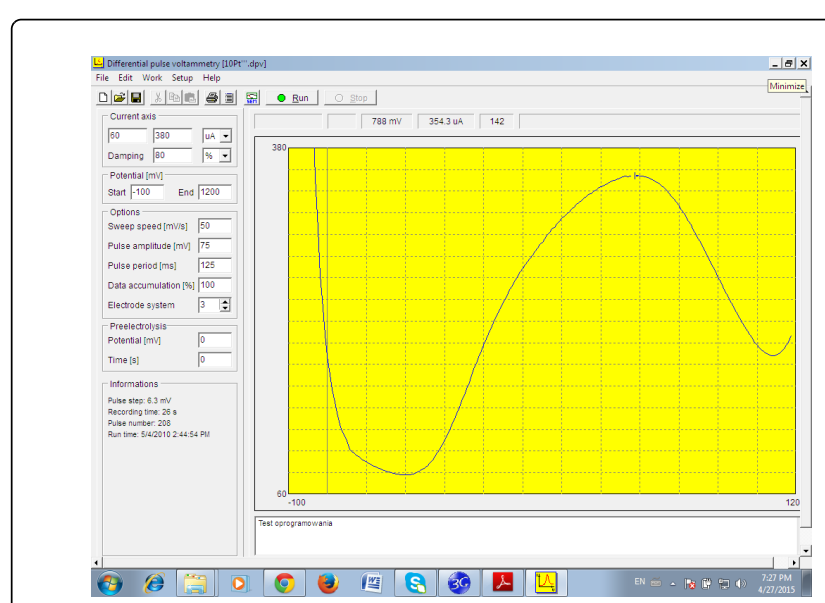

Figure 1: A differential pulse voltammogram obtained by the Author of this Editorial with a potentiostat-galvanostat, for ascorbic acid $10 \mathrm{mM}$, at a Pt working electrode, using as electrolyte a $\mathrm{KCl} 0.1$ M solution.

A study of flavonoids (quercetin, rutin, epigallocatechin gallate and catechin) voltammetric behavior and of their antioxidant characteristics has been performed, by employing an electrically heated DNA-modified carbon paste electrode. Differential pulse voltammograms were obtained at both bare and DNA modified carbon paste electrodes (Figure 2). The values of the peak potentials indicate that the most electro-oxidizable is quercetin, followed by epigallocatechin gallate and catechin. Rutin proved the most difficultly electro-oxidizable. It could be noted that the modification of the carbon paste electrode resulted in a slight peak potential shift towards more positive values, pointing to a more difficult flavonoid electrooxidation [8].

The $\mathrm{Cu}(\mathrm{II})-10$ phenanthroline complex, in the presence of $\mathrm{H}_{2} \mathrm{O}_{2}$ and ascorbic acid, was chosen as ROS generator and DNA cleavage inducer. A positive influence of the electrode temperature within the range $20-38^{\circ} \mathrm{C}$ on the detection of an enhanced DNA impairment was noted. The left undamaged DNA has been assessed by employing $\left[\mathrm{Co}(\text { phen })_{3}\right] 3+$ complex as redox indicator. Heating the DNAmodified carbon paste electrode during the incubation with the cleavage mixture exerted a beneficial influence on the sensitivity of assessing both DNA impairment and the protective effect imparted by flavonoid antioxidants [8]. 


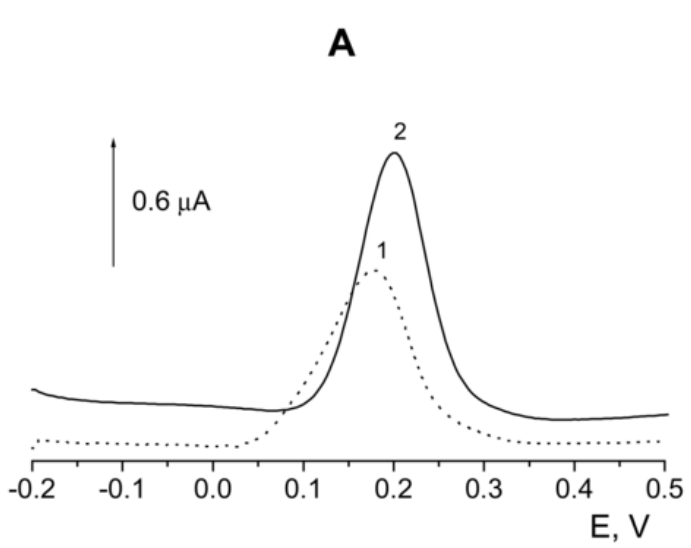

C

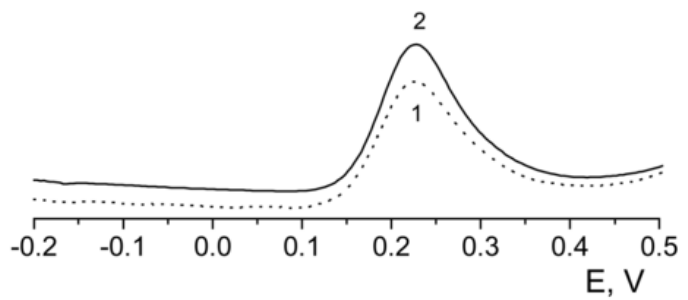

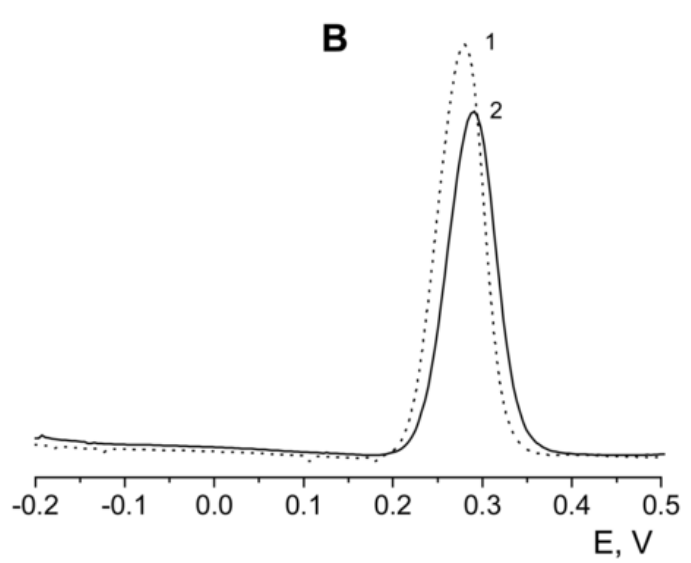

D

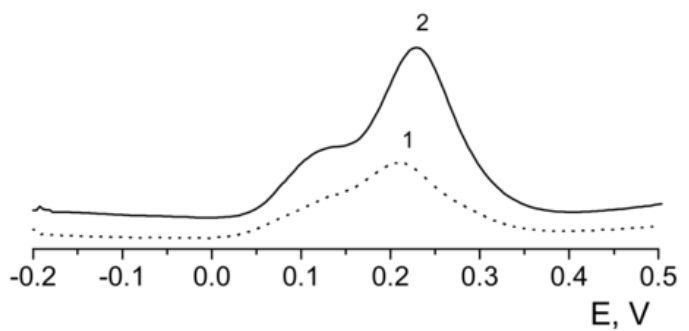

Figure 2: Differential pulse voltammograms of flavonoids, obtained at a carbon paste and a DNA modified carbon paste electrode after 5 minutes accumulation at open circuit, in solutions of: (A) $5 \times 10-7 \mathrm{M}$ quercetin, (B) $5 \times 10-7 \mathrm{M}$ rutin, (C) $5 \times 10-5 \mathrm{M}$ catechin and (D) $5 \times 10-6 \mathrm{M}$ epigallocatechin gallate. Experimental conditions: $5 \mathrm{mM}$ phosphate buffer solution $\mathrm{pH}=7.0$ containing $1 \% \mathrm{DMSO}$, pulse amplitude $=100 \mathrm{mV}$, scan rate $=25 \mathrm{mV} / \mathrm{s}$, working temperature $=22^{\circ} \mathrm{C}$, as presented in Ref. [8].

A carbon nanotubes-modified carbon paste electrode was developed for the quantitative assessment of sulphite, relying on its electrochemical (cathodic) reduction. A linear response was obtained

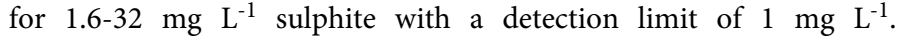
Interferent species commonly found in the analysed samples, such as ascorbic acid and sugars (fructose and sucrose) did not alter the analytical signal, allowing the determination of this preservative in beverages. Nevertheless, some red wine and red grape juice components yield a peak very close to the potential corresponding to sulphite reduction [9].

The electrochemical behavior of carmine was investigated by square-wave adsorptive voltammetry at a hanging mercury electrode, and the peak corresponding to this food dye was obtained an $-350 \mathrm{mV}$, in $\mathrm{pH}=3.0$ acetate buffer. The study of the analytical parameters showed a detection limit as low as $1.43 \mathrm{nM}$ and a relative standard deviation of $2.2 \%$. The developed voltammetric technique allowed for the determination of carmine in spiked commercially available ice cream and soft drinks [10].
The advantages of voltammetric methods are proved by the analytical performances obtained for a wide range of compounds present in foodstuffs and beverages. The analytical features depend on the voltammetric technique chosen, on the working electrode, as well as on the sample's composition.

\section{References}

1. Ahmad S, Arshad MA, Ijaz S, Khurshid U, Rashid F, Azam R (2014) Review on methods used to determine antioxidant activity. Int J Multidiscip Res Dev 1: 35-40.

2. Kounaves SP (1997) Voltammetric techniques, Ch. 37, in F.A. Settle (Ed.) Handbook of instrumental techniques for analytical chemistry, Prentice Hall, Upper Saddle River, New Jersey.

3. Bott AW (1993) Practical problems in voltammetry 2. Electrode capacitance. Curr Sep 12: 10-13.

4. Arteaga JF, Ruiz-Montoya M, Palma A, Alonso-Garrido G, Pintado S, et al. (2012) Comparison of the simple cyclic voltammetry (CV) and DPPH assays for the determination of antioxidant capacity of active principles. Molecules 17: 5126-5138. 
Citation: Pisoschi AM (2015) Voltammetry as Analytical Technique in the Study and Quantitation of Several Food and Beverage Components: An Editorial. Biochem Anal Biochem 4: e156. doi:10.4172/2161-1009.1000e156

Page 3 of 3

5. Svork L (2013) Determination of caffeine: a comprehensive review on electrochemical methods. Int J Electrochem Sci 8: 5755-5773.

6. Ngai KS, Tan WT, Zainal Z, Zawawi RM, Zidan M (2013) Voltammetry detection of ascorbic acid at glassy carbon electrode modified by singlewalled carbon nanotube/zinc oxide. Int J Electrochem Sci 8: 10557-10567.

7. Yilmaz UT, Ergun F, Yilmaz H (2014) Determination of the food dye carmine in milk and candy products by differential pulse polarography. Food Drug Anal 22: 329-335.

8. Ferancová A, Bucková M, Korgová E, Korbut O, Gründler P, et al. (2005) Association interaction and voltammetric determination of 1-aminopyrene and 1-hydroxypyrene at cyclodextrin and DNA based electrochemical sensors. Bioelectrochemistry 67: 191-197.

9. Silva EM, Takeuchi RM, Santos AL (2015) Carbon nanotubes for voltammetric determination of sulphite in some beverages. Food Chem 173: 763-769.

10. Alghamdi AH, Alshammery HM, Abdalla MA, Alghamdi AF (2009) Determination of carmine food dye (E120) in foodstuffs by stripping voltammetry. J AOAC Int 92: 1454-1459. 